\title{
Electrical field landscape of two electroceuticals
}

\author{
O. Wahlsten ${ }^{1}$, J. B. Skiba ${ }^{2}$, I. R. S. Makin ${ }^{3}$ and S. P. Apell ${ }^{1,4}$ \\ 1. Department of Physics and Gothenburg Physics Centre, Chalmers University of Technology, SE-41296 Göteborg, Sweden \\ 2. Med Minding LLC, Chandler, AZ 85226, USA \\ 3. A.T. Still University, Mesa, AZ 85206, USA \\ 4.E-mail any correspondence to: apell@chalmers.se
}

\begin{abstract}
In recent years several electrical wound management systems, so called electroceuticals, have been introduced claiming an induced electrical response in the wounded tissue. Some have external current and voltage sources while others have internal constructions aiming at creating necessary therapeutic currents. We investigate two representative electroceuticals by mapping out their electrical field landscapes using a previously developed skin model within a numerical simulation scheme. We find very strong fields from the electroceuticals of the order of $1 \mathrm{kV} / \mathrm{m}$ amenable for electrotaxic influence on pertinent cell types for wound healing. Current densities can locally be as high as $1 \mathrm{~A} / \mathrm{cm}^{2}$.
\end{abstract}

Keywords: Wound, electroceutical, skin, modeling, electric field, current, potential

\section{Introduction}

In many respects our bodies can be seen as "Body Electric" [1] where many processes in the body are inter-dependent, giving rise to situations where electrical fields are important. A life-sustaining example is the electric field associated with the polarization wave sweeping over the heart as it beats. Without the electric fields, life would cease to function. That our bodies generate electrical fields also imply that we are amenable to investigations by external electrodes [2, 3], or we can use exogenous electric fields to modulate function, e.g. cell migration in wound healing. Recently we have witnessed a steady increase in therapeutic devices and wound dressings utilizing the influence of static or dynamic electric fields [4-8] including the two electroceuticals addressed in this paper [7, 8]. At the same time we have witnessed an increased understanding of how the microscopic molecular processes are influenced by the exogenous electric fields [9, 10]. Since bacterial contamination is of importance in the wound context studies have also been made on the influence of electrical fields on bacterial cultures [11].

It should be pointed out that we are focusing on devices where possible field strengths are two orders of magnitude less than the $100 \mathrm{kV} / \mathrm{m}$, which is the typical field strength of electroporation and electrofusion on a cellular level, and the investigated devices in this paper have DC characteristics. This regime has been of interest since the early 80 's $[12,13]$ stimulated by the early work of Becker summarized in [1]. The original research stems from the pioneering frog studies by Volta more than two centuries ago [3]. A key to the understanding of the interaction between a DC wound dressing and a wound bed is to develop a realistic picture of the electrical landscape for each component, namely the dressing, the wound bed and the unperturbed skin.

Skin, an essential component in wound healing, is as important to our body integrity as the cell membrane is for the cell. Both share the property that they have an electrical potential across, of the order of 10's of $\mathrm{mV}$, however with reversed polarity. The electrical properties of skin, especially the trans-epithelial potential across epidermis, have therefore been of interest for a long time [14-16]. In an earlier paper [17] we studied the dielectric and electrical properties of a breach in the skin barrier, introducing the concept of the skin acting as an electrical capacitor. With a typical body surface area of approximately $1 \mathrm{~m}^{2}$ and an average capacitor plate distance of $100 \mu \mathrm{m}$ this internal body capacitance is substantial and of the order of $0.1 \mathrm{~F}$, since the relative dielectric constant of epidermis (capacitor filling) is roughly $10^{6}$. This is four orders of magnitude larger than water and indicates the importance of the internal structure of skin as we pointed out in [17]. Thus a wound in itself can be used to gain a better understanding of the static impedance properties of the different strata in skin.

It is very valuable to be able to extract useful, and hopefully clinically relevant information, when using electrical signals in order to better understand healing of skin related wounds, or to design external devices to mimic the electrical phenomenon of injury [17-20]. Hence the development of a non-invasive vibrating probe and a commercialized bioelectric measurement device, Dermacorder $^{\circledR}$, have confirmed the presence of an electric field in the skin [21, 22]. In [17] such experimental results were compared with our modeling of the dielectric and electrical properties of skin. With a detailed knowledge of the electrical conductivities of the various tissue components [23] we could from our results, predict and understand the generated endogenous electric patterns.

This paper is outlined in the following way. We first provide a brief physical characterization of the electroceuticals investigated in this study; Procellera ${ }^{\circledR}$ and POSiFECT $^{\circledR}$. Thereafter we present a theoretical modeling of the wound-dressing constructs. Finally we discuss our findings with respect to possible voltage and electric field actions of the dressings in a realistic wound setting. 


\section{Materials and methods}

\section{Procellera $^{\circledR}$ and POSiFECT ${ }^{\circledR}$ dressing structure}

A more detailed description of the physical characteristics of Procellera ${ }^{\circledR}$ and POSiFECT ${ }^{\circledR}$ can be found in $[10,11,24$, 25]. We start with Procellera ${ }^{\circledR}$ and show in figure 1 (top), the principal outline of this printed wireless dressing as a two dimensional square lattice of Zinc dots (diameter 1 $\mathrm{mm}$ ) and lattice distance $5.2 \mathrm{~mm}$ which is intercalated with a lattice of Silver dots (diameter $2 \mathrm{~mm}$ ) with the same lattice constant. The dot edges are $1.1 \mathrm{~mm}$ apart and the metal crystals are attached to the fibers of a polyester backing. The $\mathrm{Zn}$ dots consist of many small $\mathrm{Zn}$ granules of average size 2-10 $\mu \mathrm{m}$. The Ag crystals are of the same size; however, they tend to clump together more compared to the $\mathrm{Zn}$ crystals giving the appearance of smoother dots. Measurements of the electrical potential [11, 24] indicate that the $\mathrm{Zn}$ dots are at a voltage $-0.6 \mathrm{~V}$ and the $\mathrm{Ag}$ dots at a voltage of $+0.2 \mathrm{~V}$. This indicates the dressing acts as a halfreaction, because the measured voltage is consistent with the normal electrode potential of $\mathrm{Zn}$ itself [26].
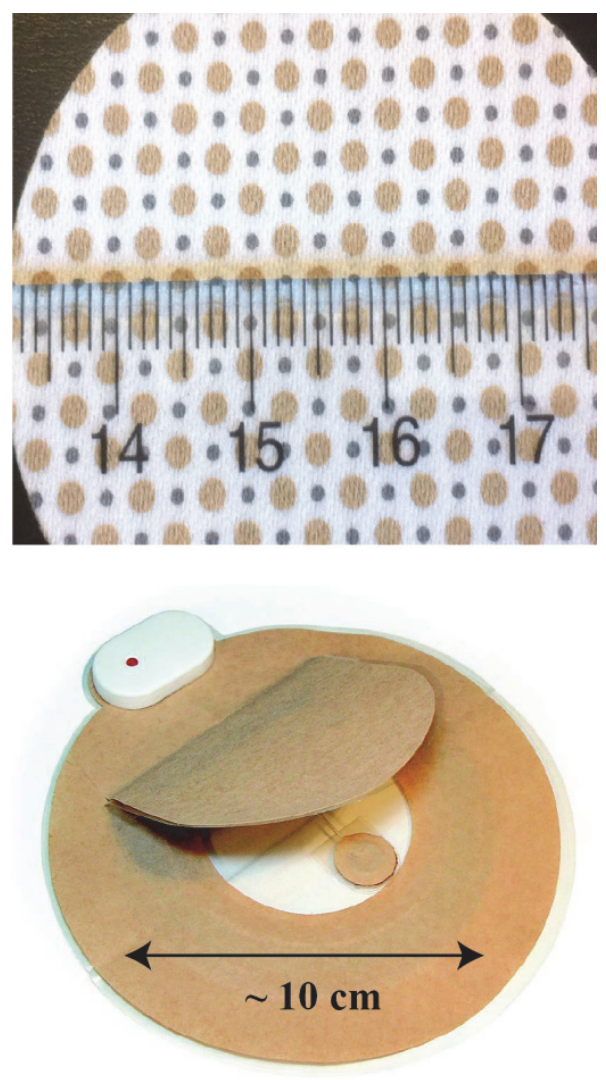

Fig.1: (top) Close-up of a Procellera ${ }^{\circledR}$ dressing. Large dots are Ag and the small dots are $\mathrm{Zn}$. (bottom) A POSiFECT ${ }^{\circledR}$ dressing. For further information we refer to references [25, 27, 28]. Both scales are in centimeters.

$\operatorname{POSiFECT}^{\circledR}[25,27,28]$ (figure 1 , bottom) is a construction made of standard dressing materials. Two electrodes deliver the necessary current to the wound and contact is facilitated with a hydrogel. One is an outer flexible metal ring (anode) placed on or partly on the peri- wound skin. For large wounds at least half of it is recommended to be on intact peri-wound skin. The other electrode (cathode) is an insulated medical grade wire to be put in the center of the wound. The system is covered with a flap to retain wound moisture and the current signal is controlled through a small electrical module unit also containing the power source in the form of two coin-cell batteries. Overall size is of the order of $10 \mathrm{~cm}$ and individual components of the order of centimeters.

We are not going into the medical aspects of these devices or their efficacy. To us they represent two different types of modalities. Procellera ${ }^{\circledR}$ has a multielectrode set-up without external control. POSiFECT ${ }^{\circledR}$ has a classical twoelectrode configuration with current control. In the next section we will now address the question of how to model these devices and then use them together with a wound model we have developed earlier in [17].

\section{Results}

\section{Model calculation of dressings}

In this and the following section we calculate the major electrostatic effects associated with the two devices described in the previous section, on unbreached and breached skin respectively. The approach in this section is used to point out the major features and electric field patterns appearing for the individual elements, namely, the wound, surrounding skin as well as the wound dressing itself. Throughout we plot both the electric potential in a color scheme and the electric field in the form of arrows with the length representing the field strength. The direction of an arrow tells us in what direction the electric force acts on a positive test charge.

Our model is implemented in the mathematical, finite element-based software Comsol Multiphysics (version 4.2a). In order to simplify things, still keeping the basic physics, we reduce the number of dimensions by using a representation of the real situation for wound and skin in the form of a rotationally symmetric wound. Thus we represent the Procellera ${ }^{\circledR}$ dressing plane (with its dots), in the form of rings of alternating metals instead. The resulting field pattern is then easily shown in a radial plot.

Our geometry is furthermore directly suited for POSiFECT $^{\circledR}$ since it has such a simple classical set-up where the electric field is mainly in the plane of the electrodes pointing radially inwards from the outer electrode (ring) towards the center electrode. Modeling of Procellera ${ }^{\circledR}$ is slightly more complicated. Figure 2 shows $\mathrm{Ag} / \mathrm{Zn}$ rings being $2 \mathrm{~mm} / 1 \mathrm{~mm}$ wide and a distance of 1.1 $\mathrm{mm}$ apart to conform with the Procellera ${ }^{\circledR}$ dimensions. We let it be air on top and epidermis below the Procellera ${ }^{\circledR}$ plane, for a dressing sitting on top of unbreached skin. The screenprinted metal Ag- $\mathrm{Zn}$ maintains potentials in saline of $+0.2 \mathrm{~V}$ and $-0.6 \mathrm{~V}$ respectively as measured in [11]. Figure 3 shows the corresponding situation for a typical POSiFECT $^{\circledR}$ situation. 

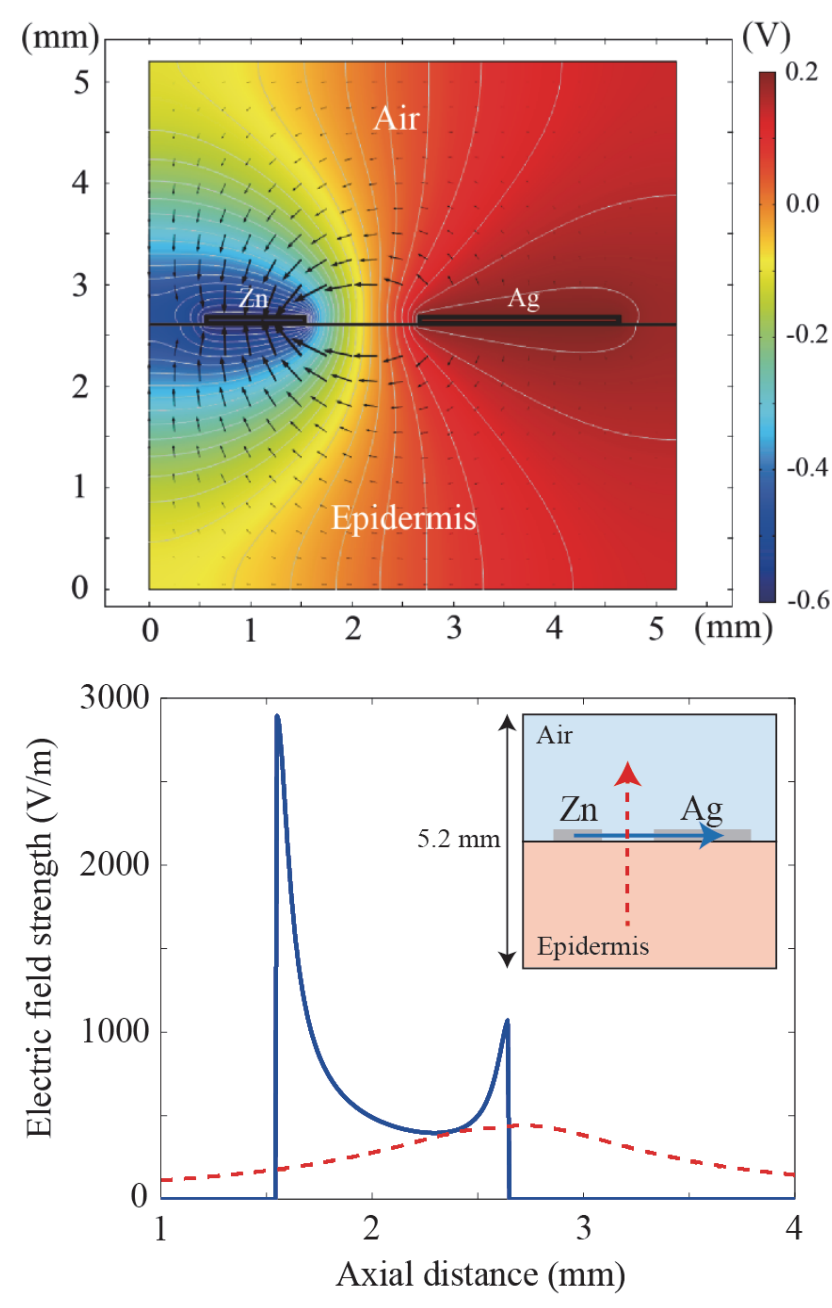

Fig.2: (top) Equipotential lines (the colors represent electrical potential according to the scale to the right) and corresponding electric field vectors for a representative cross-section through a Procellera ${ }^{\circledR}$ dressing model in the form of rings of alternating metals with length scales in accordance with the real dressing. Ag dots at potential $+0.2 \mathrm{~V}$ is twice the width of the $\mathrm{Zn}$ dots at the potential $-0.6 \mathrm{~V}$. They are separated a distance which is slightly larger than the $\mathrm{Zn}$ width. The metal rings are sitting on epidermis and have air on top. Notice the strong crowding of equipotential lines between Ag-Zn corresponding to a large electric field of the order of $1 \mathrm{kV} / \mathrm{m}$ as is detailed in the bottom figure, for clarity. (bottom) Detailed electric field plot. Notice as we move between $\mathrm{Zn}$ and $\mathrm{Ag}$ dots the field is of the order of $1 \mathrm{kV} / \mathrm{m}$ (solid blue). In the perpendicular direction it peaks at around $400 \mathrm{~V} / \mathrm{m}$ and drops off into air and epidermis (dashed red). The blue line starts at $\mathrm{x}=1$ $\mathrm{mm}$ and ends at $4 \mathrm{~mm}$. In the same way the red one starts at $\mathrm{y}=1$ $\mathrm{mm}$, ends at $4 \mathrm{~mm}$ in the direction perpendicular to the dressing and passes directly in the middle of the two dots.

Notice that in the case of modeling POSiFECT $^{\circledR}$, the dimensional scale is one order of magnitude greater compared to Procellera ${ }^{\circledR}$ ( $\mathrm{cm}$ vs $\mathrm{mm}$ ). The voltage scale of POSiFECT $^{\circledR}$ is about a factor of two greater than Procellera ${ }^{\circledR}$, however the maximum electric field strength is roughly the same, i.e. of the order of $1 \mathrm{kV} / \mathrm{m}$. Notice however that since the distance between electrodes is larger than the electrode extension in the radial direction the POSiFECT $^{\circledR}$ field strength drops off fast on a spatial scale and has a weak component out of the dressing plane.
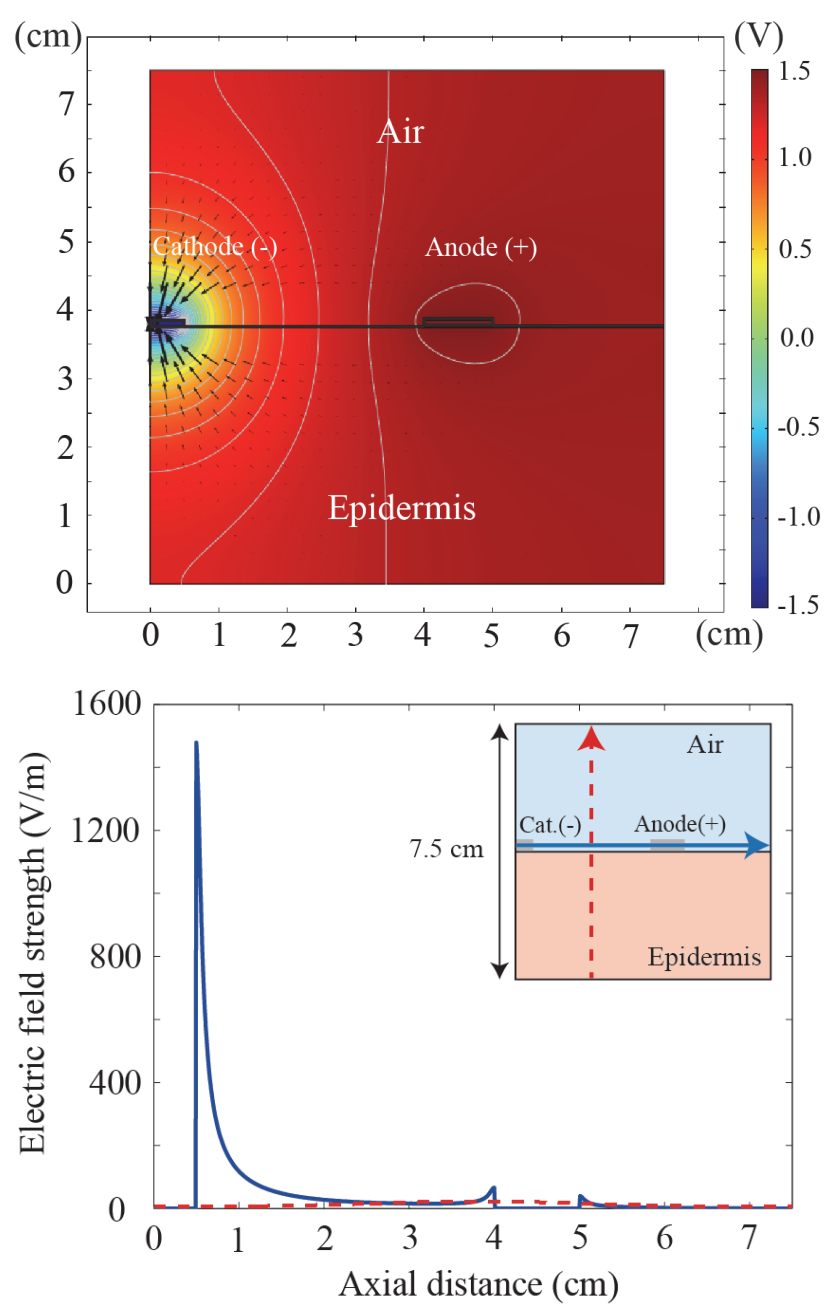

Fig.3: (top) Equipotential lines (the colors represent electrical potential according to the scale to the right) and corresponding electric field vectors for a representative cross-section through a POSiFECT ${ }^{\circledR}$ dressing model in the form of a central cathode (held at $-1.5 \mathrm{~V}$ ) in the middle and an anode electrode (ring held at +1.5 $\mathrm{V})$. The electrodes are sitting on epidermis and have air on top. (bottom) Detailed electric field plot. Notice as we move between the electrodes the field is of the order of $1 \mathrm{kV} / \mathrm{m}$ (solid blue) in the plane and vanishingly small out of the plane (dashed red). Since electrode distance is larger than width of electrode the field decays quickly away on a length-scale of the order of the size of the electrode.

In figure 4 we show the electrical potential and field arrows for a wound bed exposed to water (W) and going down to where dermis (D) begins, based on our calculations in [17]. Also this picture is a section through a circular representation of the wound construct, i.e. the full wound is achieved by rotating the cross-section around the left edge $(\mathrm{r}=0)$. The potential is shown in units of the trans-epithelial potential between stratum corneum (SC) and bottom of epidermis (E). This potential is typically in the range of 20$60 \mathrm{mV}$ [16] and has its origin in a continuous pumping of sodium and chloride ions with the latter making the skin surface slightly negative with respect to the bottom of epidermis. Notice that the corresponding electric field is directed upwards in the figure and is a possible cue for the epidermal cells to move upwards before they end up in the stratum corneum. Different types of junctions between the 
cells in the epidermis ensure that there is a minimum of leakage currents.

The thickness and electrical properties of the different strata given in figure 4 are specified in table 1 below. The interface between stratum corneum (SC) and living epidermis $(\mathrm{E})$ is assigned a trans-epithelial potential $\mathrm{V}_{0}=$ $-40 \mathrm{mV}$ with the basal level of the epidermis as ground [29, 30]. A typical field strength for a $1 \mathrm{~mm}$ thick epidermis is then $40 \mathrm{~V} / \mathrm{m}$. This model of a wound is of course simplified with flat interfaces between skin layers to bring out the major physics.

Tab.1: Summary of modeling parameters used in different regions of figure 4. $\varepsilon_{\mathrm{r}}$ is the relative dielectric permittivity and $\sigma$ is the electrical conductivity.

\begin{tabular}{|l|c|c|c|}
\hline \multicolumn{1}{|c|}{ Area } & $\begin{array}{c}\text { Thickness } \\
(\mathrm{mm})\end{array}$ & $\boldsymbol{\varepsilon}_{\mathbf{r}}$ & $\boldsymbol{\sigma}(\mathrm{S} / \mathrm{m})$ \\
\hline Wound (W) & 2.0 & 80 & 4.8 \\
\hline Stratum Corneum (SC) & 0.05 & $10^{4}$ & $4 \cdot 10^{-3}$ \\
\hline Epidermis (E) & 1.0 & $10^{6}$ & 0.22 \\
\hline Dermis (D) & 2.0 & $10^{8}$ & 0.22 \\
\hline Hypodermis (H) & 3.0 & $10^{7}$ & 0.08 \\
\hline
\end{tabular}

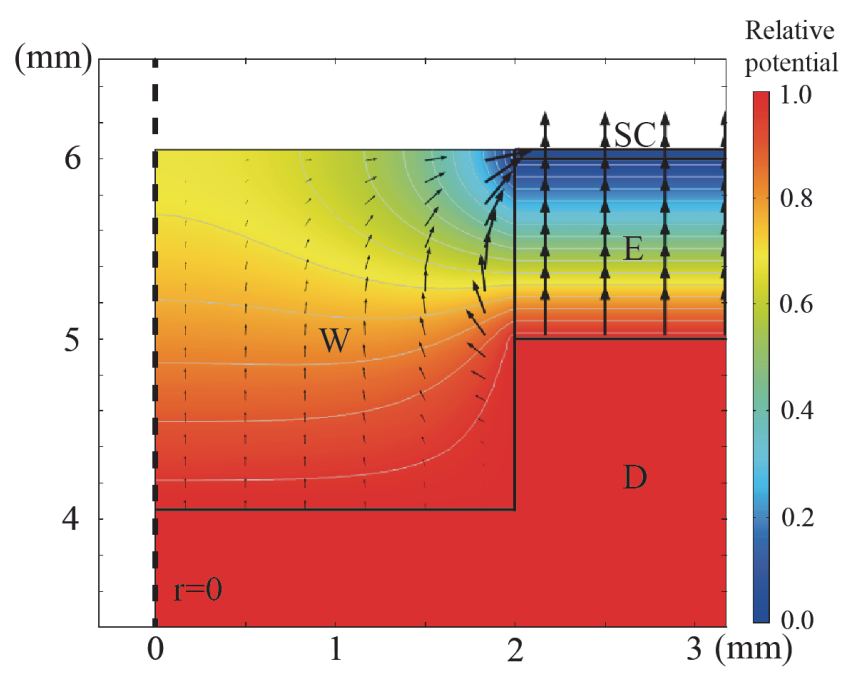

Fig.4: Calculated electrical field around a wound (W) without any wound dressing present [17]. We see a cross-section along the radius of a circular representation of the wound. Notice how the electric field is directed towards the wound in its lower part. At the top of the wound it points in the other direction. The colors represent the electric potential according to the scale to the right, in units of the trans-epithelial potential which exists over the extent of the epidermis. Typically the red color is around $40 \mathrm{mV}$ negative. There is a vanishingly small penetration of the field into dermis and hypodermis (not shown) owing to their large dielectric permittivities. The field strength in the epidermis is typically of the order of $10 \mathrm{~V} / \mathrm{m}$. Notice that the extension of the region which is influenced by creating a wound is of the order of millimeters.

When a wound is created the electric field near the wound edge develops a horizontal component that facilitates wound healing, being a cue for the movement of new cells to the wound area (electrotaxis). Studies show that important cell types in wound healing, such as fibroblasts and keratinocytes, move parallel or antiparallel to the electric field direction $[29,30]$.
Notice that in figures 2-4 the potential scales are quite different, Procellera ${ }^{\circledR}$ by itself in a saline solution generates almost a two orders of magnitude larger electric field than that from the trans-epithelial potential. The same goes for POSiFECT $^{\circledR}$.

\section{Model calculation of dressings and wound bed}

We will now simulate the wound together with the two dressings and see what implications this has for the overall electric field landscape, figures 5-7. In figure 5 we therefore show the potential and field patterns first when the dressing Procellera ${ }^{\circledR}$ is present in the wound; either with the Ag or $\mathrm{Zn}$ dot closest to the wound perimeter.

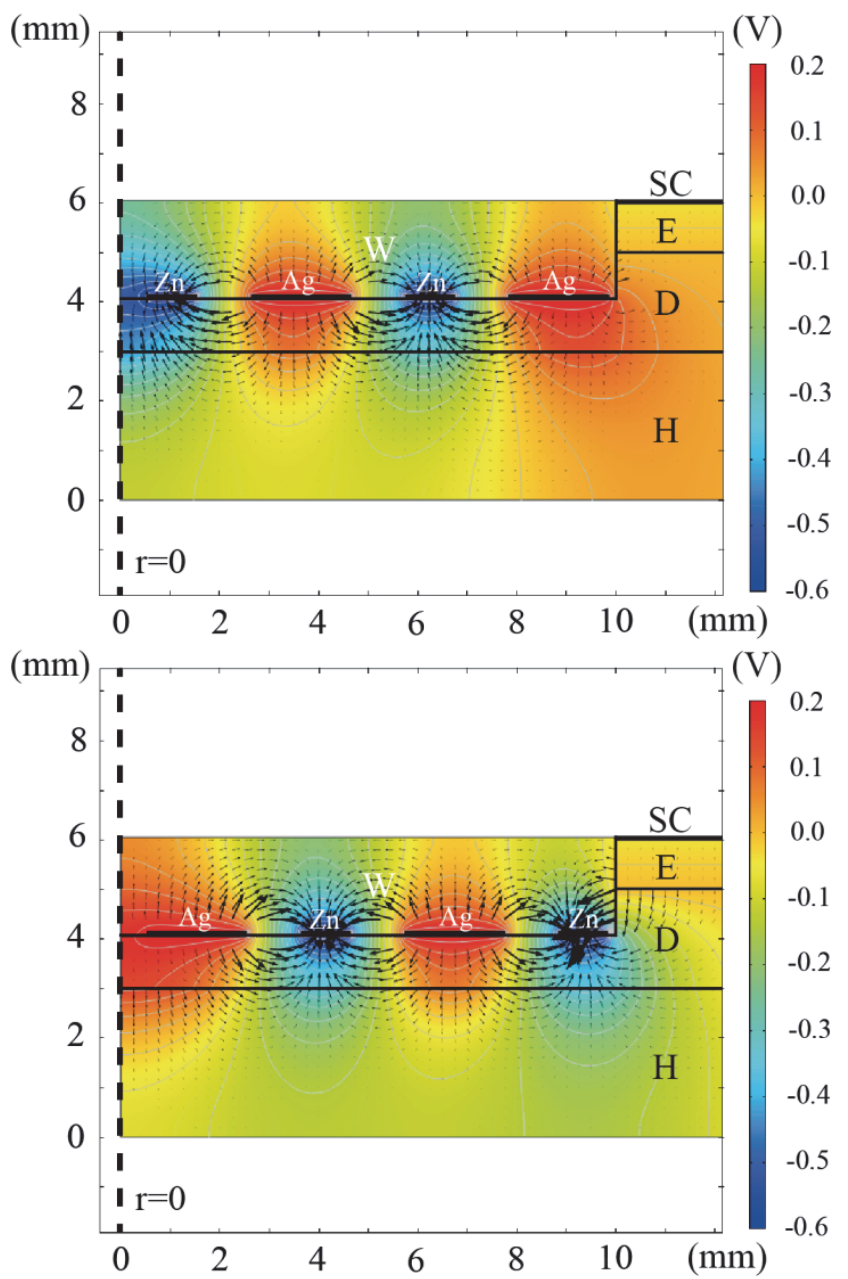

Fig.5: The electric field in the wound area with a wound dressing Procellera $^{\circledR}$ applied with $\mathrm{Ag} / \mathrm{Zn}$ closest to the wound edge (top/bottom). The reddish dots are $\mathrm{Ag}$ and the blue ones represent $\mathrm{Zn}$. The potential difference between the dots gives rise to an electric field strength that is much larger than that from the body's own field. Notice that when $\mathrm{Zn}$ is closest to the wound edge (bottom) there are large electric fields set up with large potential for influencing what happens on a microscopic scale when it comes to cell migration cued by the electric field. Notice that the electric field is not shown in the plane between the dots since it is too large.

For Procellera ${ }^{\circledR}$ we see in figure 5 that large fields are set up within the structure and in particular having $\mathrm{Zn}$ closest to the wound edge has the largest impact on the local 
electric field. Of interest in this context is of course to see what currents are driven by the electric fields calculated. Therefore, using the conductivities in table 1, we present in figure 6 a current density plot of dressing and wound together. We see that locally we can have up to $1 \mathrm{~A} / \mathrm{cm}^{2}$ which clearly is in the upper range of so called therapeutic currents. We see from the graph that the major current is mainly localized to the plane of the wound dressing and does not really enter the dermis and diminishes going out into the wound fluid.

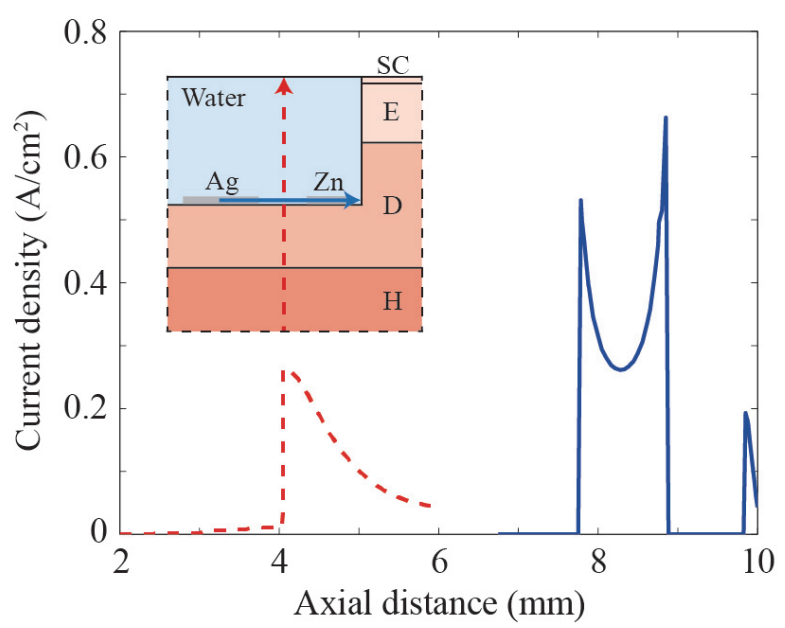

Fig.6: The electric current density in the wound area with a Procellera ${ }^{\circledR}$ wound dressing applied with $\mathrm{Zn}$ closest to the wound edge. The current density approaches $1 \mathrm{~A} / \mathrm{cm}^{2}$ in the region between the dots (solid blue) and falls off quickly in the perpendicular direction (dashed red). Especially when going down into the dermis, which has a low conductivity compared to the wound fluid.

In figure 7 we now show the potential and field patterns for the POSiFECT ${ }^{\circledR}$ dressing on the same wound bed. As the major point in space influencing the wound healing is the wound edge we only give that part of the picture. Notice therefore, that the dimensional scale of the wound where POSiFECT $^{\circledR}$ can be applied is at least five times greater than shown for Procellera ${ }^{\circledR}$. The anode ring can only ride over the rim of the wound, compared to Procellera ${ }^{\circledR}$ which conforms to the wound bed contour (Fig. 5). The potential difference $(3 \mathrm{~V})$ between the electrodes gives rise to an electric field strength that is much larger than that from the body's own field.

Using the conductivities in table 1 we can again generate a current picture which for POSiFECT ${ }^{\circledR}$ means current densities very similar to those of Procellera ${ }^{\circledR}$, i.e. of the order of $1 \mathrm{~A} / \mathrm{cm}^{2}$ (figure not included).

\section{Discussion and conclusions}

The focus of the present paper has been to characterize the physical nature of two clinically relevant wound dressings, Procellera $^{\circledR}$ and POSiFECT ${ }^{\circledR}$, as well as establishing the voltages and electric fields they provide using numerical simulations. The clinical and cellular aspects resulting from these dressings have not been the emphasis of this study.

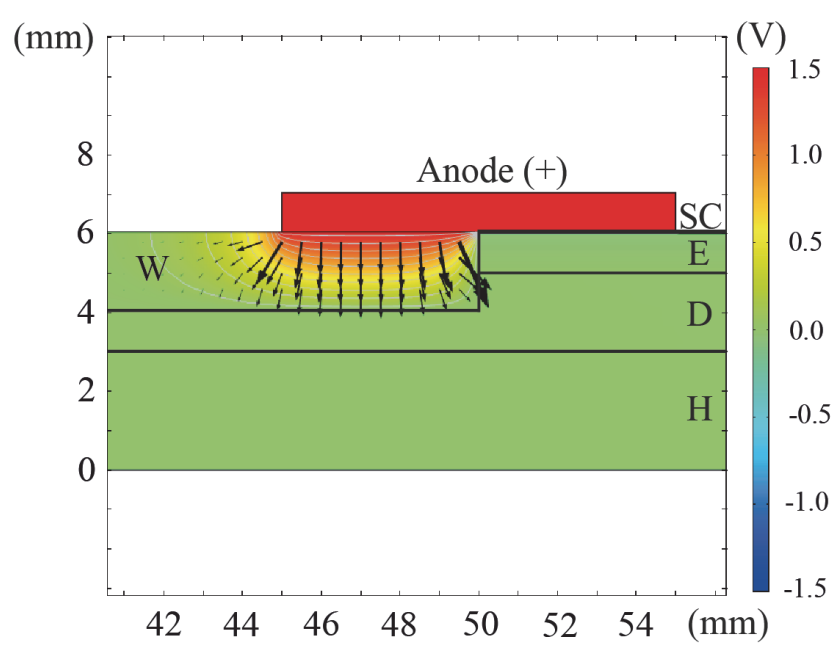

Fig.7: The electric field in the wound area with a wound dressing POSiFECT $^{\circledR}$ applied. Of interest is of course the influence of the electrode closest to the wound edge where we see major effects. We therefore only show the situation for the anode ring. Field strengths are much larger than the endogenous electric field also for this electroceutical.

Whereas POSiFECT ${ }^{\circledR}$ has a simple one anode-cathode pair construction which is rather straightforward to understand yielding electric fields and currents of known therapeutical strength, Procellera ${ }^{\circledR}$ takes more of a basic electric understanding to see how it works. With its external power source, POSiFECT ${ }^{\circledR}$ ensures reliable operation for at least 48 hours [25] while the wireless Procellera ${ }^{\circledR}$ is known to maintain its electro-potential for at least 7 days [11]. Due to its conformable matrix design, Procellera ${ }^{\circledR}$ is effective all over the wound area whereas the POSiFECT ${ }^{\circledR}$ dressing according to our calculations is very sensitive to its placement with respect to the wound edge. If too much of the outer electrode is not in contact with the wound the skin screening substantially reduces its impact.

The effects at the wound edge are crucial for a good wound healing. Both dressings have the potential of producing electric fields which are of a magnitude sufficient to override any other signal when studying cells or sheets of cells $[3,15]$. This has potentially a profound influence on cell division and direction of cell movement near the wound edge.

As stated several times the POSiFECT ${ }^{\circledR}$ with its battery driven fields is direct and simple to model. For Procellera ${ }^{\circledR}$ there are several electrochemical reactions that might occur. The simplest one we suggest to be at play, which yields a potential close to the experimentally measured one, is a lemon-battery redox reaction. Ag acts in this way as a shunt from the electrical point of view. Depending on the actual load the potentials measured can be lower than the nominal value. Furthermore, depending on reaction we might have production of hydrogen peroxide which should be beneficial for the wound healing. As in the lemon-battery the electrochemical processes can happen even without the Ag electrode present. But in order to draw power from the system we need the Ag (or another metal electrode) to provide a current loop. Based on the electrochemical 
consideration described here, the $1: 2 \mathrm{Zn}-\mathrm{Ag}$ diameter relationship in the dressing is not an essential requirement for the device's operation. In fact other dimensional ratios with optimized Ag content might conceivably be more beneficial in the design.

In summary, we have described the operation of two wound dressings with electrical modalities; so called electroceuticals. One has a simple spatial structure and the other one has a more complicated wound-conformable lattice like structure. One is driven by an external source and the other one has an inner galvanic source driving the currents which are believed to be crucial for a good wound healing when they are in the so called therapeutical range. We also want to stress the importance of the regenerative zone at the wound edge. As the skin heals that zone with its electrical activity reverts to a healthy state and moves inwards like a slow wave. Therefore the placement of any electrodes is crucial with respect to the zone since you want maximum effect of any exogenous field rather than having it acting on already healthy tissue.

\section{Acknowledgments}

P. Apell and O. Wahlsten want to express their gratitude to the original efforts of M. Elmeskog, M. Klintefjord, S. Panas, C. Spånslätt and D. Stockman in their B.Sc. thesis "En studie av plåstret Procellera ${ }^{\circledR}$ inverkan på sårläkning" [24].

\section{References}

1. Becker R, Selden G. The body electric: electromagnetism and the foundation of life: Harper Collins; 1998.

2. Pliquett U, Frense D, Schönfeldt M, Frätzer C, Zhang Y, Cahill B, et al. Testing miniaturized electrodes for impedance measurements within the beta-dispersion-a practical approach. Journal of Electrical Bioimpedance. 2010;1(1):4155. http://dx.doi.org/10.5617/jeb.111

3. McCaig CD, Rajnicek AM, Song B, Zhao M. Controlling cell behavior electrically: current views and future potential. Physiological reviews. 2005;85(3):943-78. http://dx.doi.org/10.1152/physrev.00020.2004

4. Kloth LC. Electrical stimulation for wound healing: a review of evidence from in vitro studies, animal experiments, and clinical trials. The international journal of lower extremity wounds. 2005;4(1):23-44. http://dx.doi.org/10.1177/1534734605275733

5. Moore K. Electric stimulation for treatment of chronic wounds. Journal of Community Nursing. 2007;21(1):18.

6. Ojingwa JC, Isseroff RR. Electrical stimulation of wound healing. J Invest Dermatol. 2003;121(1):1-12. http://dx.doi.org/10.1046/j.1523-1747.2003.12454.x

7. Procellera ${ }^{\circledR}($ Vomaris Inc $T, A Z$, USA).

8. POSiFECT® (Biofisica LLC A, GA, USA).

9. Martin-Granados C, McCaig CD. Harnessing the electric spark of life to cure skin wounds. Advances in wound care.
2014;3(2):127-38

http://dx.doi.org/10.1089/wound.2013.0451

10. Banerjee J, Ghatak PD, Roy S, Khanna S, Sequin EK, Bellman K, et al. Improvement of human keratinocyte migration by a redox active bioelectric dressing. Plos One. 2014;9(3):e89239. http://dx.doi.org/10.1371/journal.pone.0089239

11. Park S, Kim H, Makin I, Skiba J, Izadjoo M. Measurement of microelectric potentials in a bioelectrically-active wound care device in the presence of bacteria. Journal of wound care. 2015;24(1). http://dx.doi.org/10.12968/jowc.2015.24.1.23

12. Barker A, Jaffe L, Vanable J. The glabrous epidermis of cavies contains a powerful battery. American Journal of Physiology-Regulatory, Integrative and Comparative Physiology. 1982;242(3):R358-R66.

13. Foulds I, Barker A. Human skin battery potentials and their possible role in wound healing. British Journal of Dermatology. 1983;109(5):515-22. http://dx.doi.org/10.1111/j.1365-2133.1983.tb07673.x

14. Levin M. Large-scale biophysics: ion flows and regeneration. Trends in cell biology. 2007;17(6):261-70. http://dx.doi.org/10.1016/j.tcb.2007.04.007

15. McCaig CD, Song B, Rajnicek AM. Electrical dimensions in cell science. J Cell Sci. 2009;122(23):4267-76. http://dx.doi.org/10.1242/jcs.023564

16. Zhao M, editor. Electrical fields in wound healing - an overriding signal that directs cell migration. Seminars in cell \& developmental biology; 2009: Elsevier.

17. Wahlsten O, Apell SP. Wounds as probes of electrical properties of skin. Journal of Electrical Bioimpedance. 2010;1:63-70. http://dx.doi.org/10.5617/jeb.130

18. Pethig R. Dielectric properties of body tissues. Clinical Physics and Physiological Measurement. 1987;8(4A):5. http://dx.doi.org/10.1088/0143-0815/8/4A/002

19. Grimnes S, Martinsen ØG. Bioimpedance. Wiley Encyclopedia of Biomedical Engineering. 2006. http://dx.doi.org/10.1002/9780471740360.ebs0128

20. Gabriel C. Chapter 3, Dielectric Properties of Biological Materials. Bioengineering and Biophysical Aspects of Electromagnetic Fields: CRC Press; 2006.

21. Reid B, Nuccitelli R, Zhao M. Non-invasive measurement of bioelectric currents with a vibrating probe. Nat Protoc. 2007;2(3):661-9. http://dx.doi.org/10.1038/nprot.2007.91

22. Nuccitelli R, Nuccitelli P, Ramlatchan S, Sanger R, Smith PJ. Imaging the electric field associated with mouse and human skin wounds. Wound repair and regeneration. 2008;16(3):432-41. http://dx.doi.org/10.1111/j.1524-475X.2008.00389.x

23. Roth BJ. Chapter 10, The Electrical Conductivity of Tissues. The Biomedical Engineering Handbook (2nd edition): CRC Press; 2000.

24. Wahlsten O, Panas S. A study of Procellera ${ }^{\circledR}$ effect on wound healing June $22-2010$ (Institute Report). 2010

25. Morris C. Bio-electrical stimulation therapy using POSiFECT ${ }^{\circledR}$ RD. WOUNDS UK. 2006;2(4):112. 
26. Swartling DJ, Morgan C. Lemon cells revisited - The lemonpowered calculator. Journal of chemical education. 1998;75(2):181. http://dx.doi.org/10.1021/ed075p181

27. Butcher M. How to use Posifect ${ }^{\circledR}$ bio-electric stimulation therapy in chronic wounds. Wound Essentials. 2007;2:18693.

28. Cutting KF. Electric stimulation in the treatment of chronic wounds. WOUNDS UK. 2006;2(1):62.
29. Song B, Zhao M, Forrester JV, McCaig CD. Electrical cues regulate the orientation and frequency of cell division and the rate of wound healing in vivo. Proceedings of the National Academy of Sciences. 2002;99(21):13577-82. http://dx.doi.org/10.1073/pnas.202235299

30. Farboud B, Nuccitelli R, Schwab IR, Isseroff RR. DC electric fields induce rapid directional migration in cultured human corneal epithelial cells. Exp Eye Res. 2000;70(5):667-73. http://dx.doi.org/10.1006/exer.2000.0830 